\title{
Em Busca de Novos Paradigmas Para o Manejo da Insuficiência Cardíaca
}

\author{
Nadine Clausell, Jorge Pinto Ribeiro
}

Porto Alegre, RS

Conforme dados do Serviço Único de Saúde referentes ao ano de 1996 (Ministério da Saúde - Secretaria Executiva - DATASUS), as doenças cardiovasculares são responsáveis por $16 \%$ do custo das internações hospitalares no Brasil, representando um custo anual de quase 500 milhões de reais. Deste valor, quase 150 milhões de reais foram destinados ao pagamento de internações hospitalares por insuficiência cardíaca (IC), sendo esta a causa mais freqüente de internações por doenças cardiovasculares. Portanto, no Brasil, medidas que pudessem reduzir o número de internações por IC teriam imenso impacto social.

O manejo moderno da IC está bem definido na literatura ${ }^{1,2}$ e parece seguir diversos paradigmas ou modelos que servem como exemplos de condutas. Seguindo a mesma abordagem por nós adotada para a cardiopatia isquêmica ${ }^{3}$, um paradigma de ação médica é baseado num conceito fisiopatológico, dispõe de um método diagnóstico confiável e que permite estimar prognóstico, resultando em terapêutica capaz de controlar sintomas, diminuir morbidade e, preferencialmente, aumentar a sobrevida. $\mathrm{Na} \mathrm{a}^{\mathrm{a}}$ parte deste artigo, apresentaremos, de forma didática, os paradigmas que têm orientado o manejo da IC nas últimas décadas (quadro I), discutindo suas limitações. $\mathrm{Na} 2^{\mathrm{a}}$ parte, discutiremos alguns paradigmas que, no futuro breve, poderão melhorar o manejo desta síndrome. Finalmente, contrastaremos o manejo da IC baseado puramente no raciocínio clínico com aquele baseado na farmacologia clínica.

\section{Paradigmas atuais}

Paradigma da contratilidade - Em pacientes com IC por disfunção sistólica, o fator determinante inicial do desenvolvimento da síndrome é a redução do estado contrátil, regional ou global do ventrículo esquerdo (VE). Embora a avaliação direta da contratilidade miocárdica em seres humanos seja complexa ${ }^{4}$, a medida da fração de ejeção do ventrículo esquerdo (FEVE) por ecocardiografia ou por ventriculografia tem sido amplamente u tilizada na prática

Hospital de Clínicas de Porto Alegre e Faculdade de Medicina da Universidade Federal do Rio Grande do Sul

Correspondência: Jorge Pinto Ribeiro - Serviço de Cardiologia - Hospital de Clínicas de Porto Alegre - Rua Ramiro Barcelos, 2350 - 90035-007 - Porto Alegre, RS Recebido para publicação em 23/6/98

Aceito em 14/8/98 clínica como índice indireto de contratilidade miocárdica. A medida da FEVE permite diagnóstico da disfunção sistólica do VE e estimativa prognóstica ${ }^{5}$. Por mais de 200 anos, os digitálicos têm sido utilizados como agentes inotrópicopositivos no tratamento da IC. Entretanto, só recentemente foi possível avaliar o real impacto dos digitálicos na história natural da IC. Na realidade, a administração crônica de digoxina a pacientes em ritmo sinusal aumenta apenas discretamente $\mathrm{FEVE}^{6}$, melhora a capacidade funcional ${ }^{7} \mathrm{e} \mathrm{di}$ minui o número de internações hospitalares, porém sem afetar a sobrevida ${ }^{8}$.

Ao longo do anos 80 e 90, vários agentes com efeito inotrópico-positivo associado a efeito vasodilatador foram testados em ensaios clínicos. A despeito da melhora hemodinâmica e aumento da capacidade funcional ${ }^{9-13}$, a administração crônica desses agentes resultou, invariavelmente, em aumento da mortalidade ${ }^{14-18}$. Cabe ressaltar, por exemplo, o estudo PROMISE, que avaliou o uso de milrinone, um inibidor da fosfodiesterase por via oral, em mais de 1000 pacientes com IC classe funcional (CF) III e IV, e demonstrou um aumento de $28 \%$ na taxa de mortalidade no grupo de pacientes em uso da droga, quando comparados ao grupo que recebeu placebo ${ }^{15}$. Mais recentemente, o ensaio PRIME II avaliou a administração do agonista dopaminérgico de uso oral, ibopamina, comparado ao uso de placebo ${ }^{14}$. Esse ensaio foi suspenso pelo comitê de monitorização de segurança por aumento de mortalidade no grupo que recebeu a droga. Além disso, o uso de infusões intravenosas intermitentes de dobutamina em pacientes com IC grave também demonstrou tendência a aumento da mortalidade no grupo tratado ativamente ${ }^{19}$. Portanto, atualmente, o paradigma da contratilidade não tem apoio de ensaios clínicos para ser aplicado na grande maioria dos pacientes com IC em tratamento ambulatorial. Entretanto, o paradigma da contratilidade continua sendo válido para o manejo da IC aguda ou em quadros terminais de IC crônica, onde o estímulo inotrópico positivo pode ser fundamental para a manutenção temporária de condições vitais.
Quadro I - Paradigmas atuais no manejo da insuficiência cardíaca

Contratilidade

Cardio-renal

Hemodinâmico

Neuro-humoral

Remodelamento ventricular
Modulação simpática

Arritmia ventricular

Disfunção diastólica

Atividade física

Otimização hemodinâmica 
Paradigma cárdio-renal - Um dos primeiros sistemas que se ativam reflexamente quando existe disfunção ventricular é aquele de retenção de água e sal em decorrência da ativação do sistema renina-angiotensina-aldosterona, secundário à diminuição de perfusão renal. Como conseqüência, há aumento do volume intravascular, resultando em aumento das pressões de enchimento, tanto das cavidades esquerdas como direitas, contribuindo, por sua vez, para os sinais e sintomas congestivos dos pacientes, que resultam em dados de anamnese e exame físico, permitindo estimar o grau de retenção hidro-salina. Além disso, a radiografia de tórax, o ecodopplercardiograma e a medida invasiva das pressões de enchimento completam uma propedêutica rica, que também traz informações prognósti$\operatorname{cas}^{20}$. Há quase meio século, os diuréticos têm sido utilizados para controlar a congestão de pacientes com IC. Apesar de não haver ensaios clínicos sobre o efeito de diuréticos na sobrevida de pacientes com IC, os efeitos de melhora da qualidade de vida e capacidade funcional são tão evidentes que praticamente não há questionamentos neste sentido. Entretanto, a aplicação do paradigma cárdio-renal deve ser feita com cautela, pois a indução de diurese vigorosa pode levar à hipocalemia, aumentar o risco de arritmias graves, induzir perda de função renal por dano pré-renal, além de ativar ainda mais o sistema renina-angiotensinaaldosterona. Além disso, na falta de ensaios clínicos controlados, fica difícil definir o grau ideal de diurese indicado para cada paciente, após o controle dos sinais e sintomas congestivos na IC ${ }^{1,21}$.

Paradigma hemodinâmico - O conceito de que a précarga e a pós-carga são determinantes do desempenho ventricular está bem estabelecido há várias décadas. Como discutido anteriormente, a pré-carga pode ser estimada por métodos diagnósticos instrumentados e não instrumentados. A estimativa da pós-carga pode ser feita através da medida invasiva da resistência vascular periférica ou pela estimativa do estresse parietal, avaliado por ecocardiografia, trazendo implicações prognósticas ${ }^{22}$. Além dos diuréticos, agentes farmacológicos com efeito venodilatador, como os nitratos, também podem facilitar o controle da pré-carga. Agentes com efeito vasodilatador arteriolar, como hidralazina e bloqueadores de cálcio di-hidropiridínicos, reduzem significativamente a resistência vascular periférica e diminuem a impedância ao VE. Finalmente, prazozin e nitroprussiato de sódio apresentam efeito vasodilatador balanceado, reduzindo pré- e pós-carga. A administração aguda e crônica destas drogas vasodilatadoras resultam em melhora hemodinâmica significativa em repouso e durante o exercício ${ }^{12,23}$. Além disso, drogas com efeito venodilatador, quando administradas cronicamente, aumentam a capacidade funcional ${ }^{12,24}$.

Completando o paradigma do distúrbio hemodinâmico, o primeiro ensaio clínico $\mathrm{V}$-HeFT demonstrou que a administração crônica da associação dinitrato de isossorbida e hidralazina aumenta a sobrevida de pacientes com IC ${ }^{25}$. Além disso, esse ensaio demonstrou que o prazozin não tem efeito significativo na sobrevida desses pacientes. Entretanto, após 6 meses de tratamento, apenas 55\% dos pacientes continuavam recebendo a dose planejada de hidralazina e nitrato. Por outro lado, o ensaio clínico PRAISE, que comparou amlodipina, um bloqueador de cálcio di-hidropiridínico, com placebo, não demonstrou aumento significativo da sobrevida de pacientes com miocardiopatia isquêmica, apresentando efeito protetor em pacientes com miocardiopatia não isquêmica ${ }^{26}$. Esses achados deixaram questionamentos em relação à discordância de modulação hemodinâmica e modificação da progressão da doença. É possível que agentes vasodilatadores, apesar de melhorarem padrões puramente hemodinâmicos, exerçam efeitos indesejáveis ao ativarem o sistema renina-angiotensina-aldosterona e o sistema simpático ${ }^{26}$. Isto poderia explicar os achados do ensaio clínico V-HeFT II, que demonstraram melhor sobrevida em pacientes tratados com inibidor da convertase quando comparados àqueles que receberam os vasodilatadores hidralazina e dinitrato de isossorbida ${ }^{27}$. Portanto, a intervenção sobre o paradigma do distúrbio hemodinâmico, embora eficaz, parece limitada na capacidade de alterar a história natural da IC.

Paradigma neuro-humoral - Uma vez o miocárdio lesado, resultando em disfunção ventricular e queda do débito cardíaco, uma série de sistemas neuroendócrinos são ativados para auxiliar na manutenção da homeostase circulatória ${ }^{28}$. Dentre os sistemas essencialmente vasoconstritores e retentores de sódio, destaca-se o sistema reninaangiotensina-aldosterona, com ações tanto do ponto de vista sistêmico como tecidual, onde o aumento de angiotensina no próprio miocárdio leva à fibrose e induz hipertrofia ${ }^{29,30}$. A ativação precoce deste sistemaé claramente demonstrada pela dosagem da atividade de renina plasmática e aldosterona, com implicações prognósticas ${ }^{31}$.

A partir do trabalho de Ferreira e $\mathrm{col}^{32}$, em Ribeirão Preto, que isolaram do veneno da jararaca um peptídeo capaz de inibir a enzima de conversão da angiotensina, foram desenvolvidos agentes capazes de modular o sistema renina-angiotensina-aldosterona. A partir dos anos 80 , esses agentes passaram a ser utilizados por seus efeitos vasodilatadores, com evidente melhora clínica. Completando o paradigma neuro-humoral, os ensaios SOLVD prevenção ${ }^{33}$, SOLVD tratamento ${ }^{34}$ e CONSENSUS ${ }^{35}$ demonstraram que a inibição do sistema renina-angiotensina-aldosterona com enalapril resulta em melhor prognóstico em todas as fases da história natural da IC. Mais recentemente, os resultados do ensaio ELITE demonstraram que o bloqueio específico do receptor da angiotensina II, com losartan, resultou em menor mortalidade quando comparado com captopril ${ }^{36}$, achado que aguarda confirmação por outros ensaios. Embora o paradigma do bloqueio neuro-humoral esteja muito bem estabelecido, é importante salientar que a mortalidade ainda é elevada, mesmo em pacientes adequadamente tratados com inibidores do sistema reninaangiotensina-aldosterona. 
Paradigma do remodelamento ventricular - Ao contrário de outros mecanismos insidiosos, o infarto agudo do miocárdio (IAM) é uma condição clínica que marca o momento exato do dano miocárdio que poderá levar à IC. O remodelamento posterior do VEé proporcional ao dano inicial e pode ser quantificado de forma invasiva e não invasiva, com importantes implicações prognósticas ${ }^{37}$. Além disso, diversos ensaios clínicos têm demonstrado que a administração de diferentes inibidores da enzima de conversão pode controlar e prevenir a IC pós infarto ${ }^{38-44}$. Entretanto, mesmo com a ampla utilização de inibidores da enzima de conversão, a incidência de IC continua elevada em pacientes que se recuperam de IAM, limitando os efeitos do paradigma do remodelamento ventricular.

Recentemente, o cirurgião brasileiro Randas Batista concebeu e desenvolveu a ventriculectomia parcial, como forma de corrigir o elevado estresse parietal a que fica submetido o VE dilatado e com espessura parietal reduzida, como aquele encontrado nas formas terminais de IC por disfunção sistólica. Devido à simplicidade técnica, vários grupos cirúrgicos do país e do exterior têm utilizado este procedimento, principalmente em pacientes com IC em fase avançada. As primeiras séries de casos utilizando a cirurgia têm demonstrado melhora consistente da função ventricular esquerda ${ }^{45,46}$, confirmando a base teórica proposta por Batista. Entretanto, algumas séries que utilizaram pacientes com doença avançada têm demonstrado mortalidade de até $40 \%$ em um ano ${ }^{45}$. Uma vez que séries de pacientes com CF III e IV da New York Heart Association, que têm seu tratamento otimizado farmacologicamente, podem apresentar uma mortalidade anual de apenas $20 \%{ }^{20}$, pode-se questionar a validade da utilização da cirurgia de Batista. Apenas a realização de um ensaio randomizado poderá estabelecer o papel deste procedimento no paradigma do remodelamento ventricular.

Paradigma da modulação simpática-Da mesma forma que ocorre com o sistema renina-angiotensina-aldosterona, a diminuição da função ventricular ativa precocemente o sistema nervoso simpático. A ativação crônica do sistema nervoso simpático contribui para aumento da pós-carga, alteração do metabolismo energético miocárdico, levando a dano focal no miocárdio, com liberação de radicais livres com conseqüente produção de citocinas, que desempenharão papel importante na patogênese do remodelamento adverso do $\mathrm{VE}^{47,48}$. Esta ativação simpática pode ser constatada por níveis elevados de catecolaminas circulantes, que se associam com a gravidade ${ }^{49} \mathrm{e}$ são preditores potentes de mortalidade na $\mathrm{IC}^{50}$.

Há mais de duas décadas, investigadores escandinavos propuseram que a modulação desta ativação simpática com betabloqueadores poderia trazer importantes benefícios para pacientes com IC por miocardiopatia dilatada ${ }^{51}$. Por muito tempo este conceito foi contestado, porém, nos últimos anos, aproximadamente 3.000 pacientes com IC por disfunção sistólica foram estudados em diversos ensaios clínicos e em séries de casos com betabloqueadores, sendo possível observar-se um padrão semelhante de resulta- dos ${ }^{52}$, com diminuição dos diâmetros cardíacos e melhora da FEVE ${ }^{53,54}$. Estes parecem ser efeitos de classe, pois tais resultados foram observados com diversos agentes.

Mais recentemente, estudos têm também demonstrado benefício em termos de morbidade e mortalidade. Aqui cabe ressaltar o ensaio que utilizou o carvedilol, agente beta bloqueador não seletivo, vasodilatador e com propriedades antioxidantes em pacientes com IC em CF II e III, com FEVE $<35 \%$ já sob terapia tríplice com digital, diuréticos e inibidores da convertase. Esse estudo demonstrou que, naqueles pacientes em que a droga foi utilizada, houve uma redução de mortalidade de $67 \%$ comparado ao grupo placebo, assim como diminuição hospitalização por descompensação de $\mathrm{IC}^{55}$. Assim, o uso do carvedilol parece trazer um benefício de redução de mortalidade que é superior a qualquer outro agente utilizado para o tratamento de IC até o momento, pelo menos em pacientes em CF II e III. Apesar do entusiasmo atual com o paradigma da modulação simpática, é importante salientar que o tratamento com betabloqueadores deve ser instituído, tomando-se cuidados com relação ao estado volêmico dos pacientes, sendo freqüente a necessidade do aumento, pelo menos transitório, na doses de diuréticos, ou suspensão dos bloqueadores beta-adrenérgicos por descompensação da IC.

Paradigma da arritmia ventricular-Um elevado número de pacientes com IC apresenta morte súbita. Estes eventos podem ser devidos a episódios de assistolia, porém, mais freqüientemente estão associados à taquicardia ventricular e fibrilação ventricular ${ }^{56}$. Ao longo dos anos 60 , desenvolveu-se o conceito de que portadores de alta densidade ou complexidade de arritmia ventricular estariam expostos a um risco aumentado de morte súbita. Como já discutido para a cardiopatia isquêmica ${ }^{3}$, o diagnóstico e a avaliação prognóstica destas arritmias podem ser feitos através de vários métodos não invasivos e invasivos. Até o final dos anos 80, pacientes com alta densidade e complexidade de arritmias ventriculares vinham sendo tratados com agentes antiarrítmicos, na expectativa de que a diminuição das arritmias tivesse como consequiência a diminuição da morte súbita. Entretanto, este paradigma foi completamente negado com os resultados do ensaio clínico CAST ${ }^{57,58}$, no qual pacientes que se recuperaram de IAM, com disfunção ventricular e arritmia ventricular, foram randomizados para receber os antiarrítmicos encainida, flecainida, moricizina ou placebo. A despeito da diminuição das arritmias no grupo que recebeu os antiarrítmicos, esses pacientes apresentaram maior mortalidade. Da mesma forma, a orientação da terapêutica farmacológica das arritmias ventriculares utilizando métodos não invasivos ou estudo eletrofisiológico invasivo tem sido desapontadora ${ }^{59}$.

Em contraste com estas observações, ensaios clínicos com a administração de amiodarona têm mostrado resultados menos desapontadores. O ensaio argentino GESICA ${ }^{60}$ randomizou pacientes com IC que não apresentavam obrigatoriamente arritmias para amiodarona ou placebo. Esse estudo mostrou um efeito favorável da amiodarona na 
sobrevida dos pacientes. Por outro lado, o ensaio clínico americano CHF-STAT ${ }^{61}$ não mostrou diferença significativa em sobrevida entre pacientes tratados com amiodarona ou placebo. Diferenças fundamentais entre estes dois ensaios incluíram o predomínio de miocardiopatia dilatada e um número expressivo de pacientes em CF IV entre os pacientes do estudo argentino, e predomínio de miocardiopatia isquêmica e pacientes menos graves no estudo americano. Em pacientes com disfunção ventricular que se recuperam de infarto do miocárdio, o ensaio EMIAT também não demonstrou efeito protetor da amiodarona ${ }^{62}$. Por outro lado, em pacientes com arritmia ventricular que se recuperam de infarto do miocárdio, o ensaio CAMIAT foi capaz de demonstrar efeito protetor da amiodarona ${ }^{63}$. Portanto, dentre os agentes antiarrítmicos disponíveis, a amiodarona se destaca como aquele que pode ter benefício em alguns pacientes, porém com resultados limitados.

Mais recentemente, o paradigma da arritmia ventricular tem sido reativado com a disponibilidade de métodos mais eficazes de prevenção da morte súbita. O ensaio MADIT ${ }^{64}$ demonstrou que o uso de desfibriladores implantáveis reduz a mortalidade de pacientes com cardiopatia isquêmica, FEVE $<36 \%$, taquicardia ventricular não sustentada espontânea e taquicardia ventricular sustentada induzível em estudo eletrofisiológico. Da mesma forma, o ensaio AVID ${ }^{65}$ confirmou que os desfibriladores implantáveis protegem pacientes ressuscitados de fibrilação ventricular, com taquicardia ventricular e síncope, ou com taquicardia ventricular e comprometimento hemodinâmico. Como a maioria dos pacientes admitidos no AVID apresentavam IC ou disfunção sistólica do VE, parte desses resultados poderia ser extrapolada para esse grupo de pacientes. Por outro lado, no ensaio CABG PATCH ${ }^{66}$, pacientes com cardiopatia isquêmica, com cirurgia de revascularização planejada, FEVE $<36 \%$ e alteração no eletrocardiograma de alta resolução foram randomizados para receberem desfibrilador implantável ou acompanhamento clínico. Nesse grupo com risco relativamente baixo para morte por arritmia ventricular, o uso de desfibrilador implantável não trouxe benefícios de sobrevida. Portanto, as informações disponíveis até o momento indicam que os desfibriladores implantáveis devem ser considerados para o tratamento de pacientes com IC e arritmias de alto risco. Devido a sua capacidade de cardioversor-desfibrilador e também de marcapasso, estes dispositivos podem proteger contra a morte súbita por taquiarritmia e também por bradiarritmia. Entretanto, o elevado custo destes aparelhos torna sua aplicação em nosso meio ainda muito restrita, diminuindo o impacto do paradigma da arritmia no manejo da IC.

Paradigma da disfunção diastólica - Até os anos 80 , pacientes com IC sem evidência de valvulopatia, doença pericárdica ou miocardiopatias hipertrófica e restritiva eram manejados partindo do pressuposto de que havia comprometimento da contratilidade ventricular esquerda. Com a ampla utilização de métodos diagnósticos não invasivos, capazes de quantificar a função sistólica e diastólica do VE, como a ecodopplercardiografia e a ventriculografia radioisotópica, ficou evidente que até um terço dos pacientes apresentando IC tinha função sistólica preservada ${ }^{67}$. O entendimento da etiopatogenia e fisiopatologia da disfunção diastólica isolada ou em associação com disfunção sistólica está bem fundamentado. Após dano miocárdico, ocorre um processo reparativo, onde se observa acúmulo de colágeno, formando áreas fibróticas e que levam a uma diminuição da complacência ventricular ${ }^{68,69}$. Outra causa importante de disfunção ventricular inclui a hipertrofia que acompanha situações de sobrecarga de pressão, que depende da ação da aldosterona no miocárdio ${ }^{70}$. A presença de disfunção diastólica com função sistólica preservada associa-se com bom prognóstico, porém, a identificação de padrão restritivo de enchimento ventricular em pacientes com disfunção sistólica está associada com prognóstico sombrio ${ }^{67}$.

Para completar o paradigma da disfunção diastólica, vários agentes farmacológicos têm efeito benéfico em diferentes aspectos do enchimento ventricular. $\mathrm{O}$ tratamento inespecífico da disfunção diastólica pode incluir ações sobre a pré-carga, com diuréticos e venodilatadores, ou sobre o tempo de diástole, com digitálicos, betabloqueadores e bloqueadores de cálcio. Além disso, medidas específicas sobre o mecanismo responsável pela disfunção, como terapia anti-isquêmica, ou fármacos que interferem no processo ativo do relaxamento, como os bloqueadores dos canais de cálcio, ou os inibidores da fosfodiesterase, também podem ser utilizados ${ }^{68}$. Para aquelas condições em que a disfunção diastólica é decorrente de hipertrofia ventricular, estratégias que controlem a pressão arterial (PA), levando à redução da hipertrofia ventricular, e estratégias cirúrgicas de correção da sobrecarga de pressão também terão impacto positivo ${ }^{68,71}$. Finalmente, drogas que inibem o sistema renina-angiotensina-aldosterona parecem exercer efeitos benéficos no relaxamento ventricular e contribuem a longo prazo para redução do grau de hipertrofia ventricular ${ }^{72}$. Uma vez que pode haver escape do bloqueio deste sistema, ações mais específicas, como o uso dos bloqueadores da angiotensina $\mathrm{II}^{73}$, ou o bloqueio da aldosterona com espironolactona ${ }^{74}$, também podem ser considerados. Embora todas estas intervenções tenham efeito comprovado, não há ensaios randomizados demonstrando redução de desfechos clínicos para consolidar o paradigma da disfunção diastólica.

Paradigma da atividade física - Até o início dos anos 80, acreditava-se que pacientes com IC não deveriam se exercitar. Ao longo dos últimos 15 anos, a fisiopatologia do exercício na IC foi estudada em profundidade, tendo sido demonstrado, de maneira inequívoca, que grande parte da limitação funcional dos pacientes é determinada por alterações vasculares, metabólicas e musculares esqueléticas exatamente determinadas pela inatividade física ${ }^{75,76}$. A capacidade funcional dos pacientes pode ser determinada de maneira objetiva através de questionários ${ }^{77}$ ou teste de esforço com ou sem análise de gases expirados ${ }^{12}$, resultando em importante implicação prognóstica ${ }^{78}$. Completando o paradigma da atividade física, ensaios clínicos têm demons- 
trado que programas de condicionamento aeróbio resultam em aumento significativo da capacidade funcional, que pode ser maior e adicional àquele induzido pela administração crônica de agentes farmacológicos ${ }^{79}$. O aumento da capacidade funcional com o condicionamento físico acompanha-se de melhora da função endotelial ${ }^{80}$, do sistema nervoso autônomo ${ }^{79}$, das respostas metabólicas e neuromusculares ${ }^{81}$. Embora haja consenso na recomendação de atividade física regular para pacientes com IC compensada, ainda não existem estudos demonstrando que esta intervenção possa alterar a sobrevida dos pacientes, limitando portanto o paradigma da atividade física.

Paradigma da otimização hemodinâmica - Com base no princípio da lei de Frank-Starling, a estratégia de obter o máximo rendimento do VE através da manutenção de altas pressões de enchimento popularizou-se no manejo de pacientes com IC. Enquanto isto é de fato válido em situações de falência aguda do VE pós-IAM, em que as dimensões das câmaras cardíacas são ainda normais e há perda de complacência ventricular, isto não é o que acontece quando há IC avançada, onde, na verdade, há dilatação importante das cavidades cardíacas. Nesta situação, ocorre dilatação do anel mitral e piora do grau de regurgitação mitral. Por outro lado, a dilatação ventricular também leva à distensão dos sarcômeros além da sua capacidade de gerar força eficientemente ${ }^{82}$. Estas duas observações levaram Stevenson e col a propor, nos últimos anos, mudanças marcantes na manejo de pacientes com IC avançada.

Um aspecto fundamental para o sucesso desta abordagem é o entendimento de que a avaliação clínica desses pacientes freqüentemente é enganosa, no que diz respeito ao grau de congestão presente. Quando pacientes com IC grave, com FEVE $<20 \%$, foram estudados com monitorização hemodinâmica, ficou evidente que, mesmo aqueles que não apresentavam sinais clínicos de congestão, como estertores pulmonares, turgência jugular e edema periférico, tinham pressão capilar $>25 \mathrm{mmHg}$ e resistência vascular periférica $>2.800$ dinass $\mathrm{cm}^{-583}$. O exame clínico predominantemente "silencioso" nesses pacientes tende a estimular uma abordagem que reforça a manutenção de altas pressões de enchimento para otimizar o rendimento ventricular. Contrariando-se a esta perspectiva, Stevenson e col realizaram estudos em que vasodilatadores e diuréticos foram utilizados em altas doses, objetivando reduções importantes tanto da pressão capilar pulmonar como da resistência vascular sistêmica. Estes estudos contribuíram, de forma substancial, para o entendimento dos mecanismos fisiopatológicos envolvidos na IC, uma vez que demonstraram que a obtenção de pressões de enchimento próximas do normal (12 a $15 \mathrm{mmHg}$ ) e de resistência vascular periférica em torno de 1.200 dinas $\mathrm{s}^{-5}$ associam-se com melhora importante do rendimento cardíaco ${ }^{84}$. Esta estratégia também se mostrou útil para definir prognóstico de pacientes com IC avançada, uma vez que a não obtenção de diminuição de pressão capilar e melhora do rendimento cardíaco em alguns pacientes associa-se à mortalidade maior, fazendo que apenas esses pacientes sejam logo encaminhados para a lista de transplante cardíaco ${ }^{85}$. Os demais, que correspondem à maioria, podem ser mantidos sob cuidados ambulatoriais em centro especializado para o tratamento de IC grave ${ }^{20}$. De fato, estudos posteriores demonstraram que é possível manter estes pacientes com pressões baixas em nível ambulatorial, desde que haja uma auto-educação com uso flexível de diuréticos baseado no peso diário, e que isto se associa com sobrevida em torno de $60 \%$ em 12 meses para pacientes que de outra forma estariam sendo colocados em lista de transplante cardíaco ${ }^{20,86}$. No contexto atual, o paradigma da otimização hemodinâmica tem ganho aceitação, porém está totalmente baseado em séries de casos cuidadosas, não havendo ensaios clínicos randomizados que confirmem seu real papel no manejo contemporâneo da IC.

Perspectiva dos paradigmas atuais-Nas últimas décadas, o manejo da IC evoluiu bastante, permitindo uma melhor qualidade de vida e diminuição da mortalidade de um número apreciável de pacientes. Entretanto, a revisão da mortalidade dos grupos tratados por agentes eficazes em ensaios clínicos contemporâneos aponta para um quadro ainda muito desapontador. Pacientes com disfunção ventricular e sem evidência de IC apresentam uma mortalidade anual de 2 a $10 \%{ }^{33,38}$. Em pacientes em CF II a III da NYHA, a mortalidade anual pode ser de 3 a $30 \%$ 25,27,36,55,87. Finalmente, pacientes em classe IV têm uma mortalidade estimada em 50 a $60 \%{ }^{35}$. Como estas estimativas são feitas no mundo irreal dos ensaios clínicos, acredita-se que a efetividade dos paradigmas atuais seja ainda pior, indicando que somente o desenvolvimento de novos paradigmas permitirá alterar drasticamente o curso natural desta síndrome.

\section{Novos paradigmas}

Paradigma da disfunção endotelial - A patogênese da IC envolve disfunção miocárdica e também alterações vasculares. Estas dependem de anormalidades que envolvem o endotélio vascular e são responsáveis por muitos dos sinais e sintomas presentes no pacientes, além de participarem do processo de remodelamento ventricular e vascular característicos da síndrome. O padrão de disfunção endotelial classicamente descrito na IC é do tipo endotélio-dependente, sendo caracterizado como em parte decorrente de deficiência da liberação de óxido nítrico e em parte secundário a um aumento da síntese de endotelina-1, um potente vasoconstritor ${ }^{88}$. Este perfil indica um desequilíbrio entre agentes vasodilatadores e vasconstritores, levando a um tônus vasomotor basal aumentado e reserva vasodilatadora diminuída em pacientes com IC. A etiologia desta disfunção endotelial ainda é incerta, porém alguns estudos apontam para um efeito deletério do aumento do estresse oxidativo presente na IC como pelo menos parcialmente envolvido ${ }^{48}$. De fato, radicais livres de oxigênio podem causar lesão da célula endotelial de várias formas, diminuir a meia-vida do óxido nítrico e inibir ação da óxido nítrico sintetase na célula endotelial ${ }^{87}$. 
Tanto as células miocíticas como endoteliais ou endocárdicas são capazes de produzir endotelina-1. Além disso, miócitos expressam ambos subtipos de receptores para endotelina: receptor A e receptor B. Embora o miocárdio normal possa produzir endotelina, existe uma produção aumentada na $\mathrm{IC}^{89}$. Além disso, níveis elevados de endotelina têm sido considerados como indicadores de mau prognóstico nesta síndrome ${ }^{90}$. O papel que a endotelina desempenha, comprometendo de forma adversa o remodelamento, possivelmente se relaciona com indução de vasoespasmo focal, miocitólise e aumento de fibrose. É possível também que um certo grau de apoptose, ou morte celular programada, seja causado por endotelina ${ }^{91}$. O conjunto de dados envolvendo endotelina na patogênese do remodelamento é apoiado pelo estudo que utilizou um agente bloqueador do receptor da endotelina, bosentam, demonstrando uma diminuição da PA média, pressão capilar pulmonare resistência vascular sistêmica, com aumento do índice cardíaco em pacientes com $\mathrm{IC}^{92}$. Portanto, este é o primeiro estudo apontando que a endotelina de fato exerce efeitos deletérios sobre o sistema cardiovascular, e que seu antagonismo pode melhorar o padrão hemodinâmico característico da IC. Como a endotelina pode ser medida no sangue periférico, estudos de intervenção com outros desfechos, como função ventricular, capacidade funcional e sobrevida serão necessários para estabelecer este novo paradigma

A presença de disfunção endotelial participa de modo significativo na limitação ao exercício característica dos pacientes com IC, pois existe uma diminuição da vasodilatação dependente de fluxo que é por sua vez óxido nítrico-dependente ${ }^{93}$. Além disto, alterações na estrutura vascular contribuem para uma limitação ao aumento de fluxo necessário. Este remodelamento vascular é caracterizado por hialinose e espessamento da membrana basal já identificado na musculatura esquelética e na vasculatura da pele ${ }^{94}$. É possível que estas alterações estruturais vasculares sejam decorrentes de regulação neuro-humoral e hemodinâmicas.

Além de participar no processo vascular periférico, a disfunção endotelial está possivelmente envolvida no processo de remodelamento ventricular. Oenrijecimento progressivo dos vasos da microcirculação miocárdica leva a um aumento da resistência vascular miocárdica, aumentando a pós-cargae, por sua vez, levando à disfunção ventricular progressiva $\mathrm{e}$ hipertrofia. Por outro lado, a perda ou redução da reserva vasodilatadora coronária pode causar isquemia e perda de miócitos e incorporação de fibrose, em conjunto, contribuindo para um progressivo remodelamento ventricular ${ }^{95}$.

Em suma, a disfunção endotelial parece estar inequivocamente presente na IC e alguns dados sugerem participação ativa na progressão da síndrome, tanto por suas conseqüências vasculares periféricas como em nível miocárdio. Para que um papel causal seja, no entanto, estabelecido é necessário que estudos com uso de agentes, que melhorem a função endotelial, demonstrem benefícios com relação a sintomas e sobrevida. Até o momento, relatos têm apresentado efeitos benéficos na função endotelial com uso crônico de inibidores convertase e nitroglicerina de uso agudo na IC ${ }^{96,97}$. Já o efeito de agentes antioxidantes específicos, como vitamina $\mathrm{C}$ e $\mathrm{E}$ no endotélio de pacientes com IC permanece não estudado. O uso de L-arginina, ao contrário, já foi associado à melhora da capacidade funcional ao exercício, melhora do perfil hemodinâmico e melhora da vasodilatação endotélio-dependente ${ }^{95}$. Embora betabloqueadores como carvedilol, com potente efeito antioxidante, já tenham demonstrado benefício de sobrevida, o seu papel na função endotelial ainda não foi esclarecido. Portanto, o círculo ainda não pode ser considerado fechado para completar o paradigma da disfunção endotelial na IC.

Paradigma da apoptose-Embora os mecanismos centrais envolvidos no remodelamento ventricular estejam associados à hipertrofia de miócitos e alteração no conteúdo de tecido fibroso, atualmente considera-se que a morte celular programada, ou apoptose, também participa neste processo $^{56}$. Apoptose é uma característica normal dos processos de desenvolvimento de vários tecidos. Diferentemente da necrose, este é um processo fortemente controlado por fenômenos moleculares e bioquímicos, determinados por regulação gênica. Apoptose foi inicialmente considerada como passível de ocorrer apenas em células, que cursam um ciclo celular convencional, portanto, remotamente envolvendo células terminalmente diferenciadas como miócitos. No entanto, estudos experimentais têm demonstrado a presença de apoptose em miocárdio pós-dano de reperfusão, infarto agudo, estiramento mecânico, sobrecarga de pressão, entre outros ${ }^{98}$. Além disto, recentemente Narula e col demonstraram a presença de células apoptóticas no miocárdio de pacientes com diagnóstico de miocardiopatia dilatada em estágio avançado ${ }^{99}$. O significado desses achados, entretanto, ainda é objeto de controvérsia no sentido de estabelecer implicações patogênicas e conseqüente aplicação terapêutica. As observações de Olivetti e col apontam para um percentual menor do que $0,2 \%$ de células com aparência apoptótica em pacientes com miocardiopatia dilatada ${ }^{100}$. Embora este percentual possa parecer muito reduzido para trazer conseqüências desastrosas ao músculo cardíaco, o reconhecimento de que apoptose é um fenômeno transitório, durando talvez apenas algumas horas, sugere que a perda de $0,2 \%$ de células por dia pode, ao longo de anos, levar a uma diminuição significativa da massa muscular.

Ao se considerar os múltiplos mecanismos celulares e moleculares envolvidos na patogênese do remodelamento ventricular na IC, é importante salientar que a apoptose pode ser considerada como um evento conseqüente à ativação anormal de vários desses mecanismos, como por exemplo, ativação simpática, angiotensina, citocinas, estresse mecânico, entre outros ${ }^{88}$. No momento, o estudo histológico da apoptose a partir de biópsia endomiocárdica não tem aplicabilidade clínica.

Porém, o paradigma incompleto da apoptose pode ser entendido como um fator presente na patogênese desta síndrome, onde ao menos estudos iniciais indicam que intervenções terapêuticas atuais possam estar atuando. De fato, estudos experimentais em coelhos submetidos à lesão 
de reperfusão demonstraram que o uso de carvedilol reduziu significativamente a ocorrência de apoptose no miocárdio. Especula-se que o benefício exercido pelo carvedilol seja decorrente tanto do seu efeito betabloqueador como antioxidante, já que a liberação de radicais livres de oxigênio parece estar envolvida na indução de apoptose. Portanto, é possível especular que, pelo menos parte do benefício de sobrevida obtido com uso de carvedilol em pacientes com IC, seja através da influência que este possa exercer sobre os mecanismos envolvidos no remodelamento, incluindo a redução do grau de apoptose ${ }^{101}$. Estudos em humanos, analisando padrão de apoptose observado antes e após o uso deste tipo de fármacos, ou outros que modulem a ativação neuro-humoral, são desejáveis para esclarecer um potencial efeito causal modulável para a apoptose no desenvolvimento da IC. Além disso, esperase que intervenções mais específicas sobre a apoptose venham a ser desenvolvidas.

Paradigma imuno-inflamatório - Atualmente, a miocardiopatia dilatada pode ser classificada como resultado de doença cardíaca viral, miocardite autoreativa e processo inflamatório crônico ou ativo do miocárdio ${ }^{102}$. Estima-se que miocardite viral é a etiologia responsável por até $30 \%$ dos casos de IC por miocardiopatia dilatada e que, aproximadamente, $50 \%$ dos casos apresentem evidências de atividade humoral ou celular persistente ${ }^{103,104}$. Como a biópsia endomiocárdica permite evidenciar alterações anatomopatológicas compatíveis com o processo inflamatório e estimar o prognóstico, com possibilidade de tratamento específico, o paradigma imuno-inflamatório poderia ser proposto. Entretanto, um ensaio clínico randomizado não demonstrou benefício de tratamento com ciclosporina e corticosteróides para pacientes com diagnóstico presumido de miocardite ${ }^{105}$. Os resultados desse estudo têm sido criticados, principalmente por que os pacientes não foram selecionados de acordo com seu estado imunológico ou viral por técnicas mais precisas. O ensaio ESETCID ${ }^{106}$, atualmente em desenvolvimento, poderá responder, pelo menos em parte, algumas destas questões. Nesse estudo, pacientes com miocardite em atividade e crônica estão sendo randomizados para diferentes formas de tratamento específico para o quadro etiológico: naqueles com quadro autoimune negativo para vírus está sendo usado azatioprina e prednisona; hiperimunoglobulinas para miocardite por citomegoalovírus; e interferon-alfa para pacientes com miocardite positiva para enterovírus. Enquanto os resultados desse estudo não estiverem disponíveis, o paradigma imuno-inflamatório ainda estará incompleto.

Recentemente, vários mediadores biológicos de origem inflamatória, chamados de citocinas, têm sido encontrados em concentrações elevadas no sangue de pacientes com IC. Citocinas são moléculas protéicas de baixo peso molecular (15 a $30 \mathrm{kd}$ ), sintetizadas por diferentes células secundariamente a diferentes estímulos. Até o momento, duas classes maiores de citocinas têm sido estudadas como exercendo papeis importantes na patogênese da IC: agen- tes vasoconstritores, como a endotelina-1, e agentes vasodepressores, como o fator de necrose tumoral alfa (FNT- $\alpha$ ) e a interleucina-6. Nesta apresentação didática, o papel da endotelina foi abordado no paradigma da disfunção endotelial, e apenas examinaremos o papel do FNT- $\alpha$ como mediador inflamatório, por ser este talvez o mais bem estudado entre os diversos marcadores descritos na literatura.

A presença de FNT- $\alpha$ tem sido consistentemente associada à presença de IC. Vários estudos demonstram níveis elevados deste marcador em pacientes com IC avançada, havendo inclusive alguns relatos apontando níveis de FNT- $\alpha$ como marcadores de mau prognóstico ${ }^{107,108}$. Neste sentido, um estudo envolvendo pacientes do ensaio SOLVD e pacientes aguardando transplante cardíaco demonstrou haver uma associação entre níveis elevados e CF III e IV, quando comparados a controles normais ${ }^{109}$. Enquanto algumas controvérsias existem com relação ao papel desempenhado por esta citocina na progressão da doença, vale salientar que alguns aspectos característicos na IC podem ser explicados por concentrações elevadas desta citocina, como por exemplo, disfunção ventricular, edema pulmonare remodelamento ventricular ${ }^{47}$. Portanto, alguns sintomas e sinais presentes em pacientes com IC podem, pelo menos em parte, ser secundários a efeitos do FNT- $\alpha$. Para que o paradigma inflamatório na IC, envolvendo esta citocina seja sustentável, algumas questões devem ser melhor esclarecidas. Por exemplo, é sabido que apenas 30-40\% dos pacientes com IC apresentam níveis elevados de FNT- $\alpha$, não estando clara a razão pela qual pacientes com graus semelhantes de gravidade da síndrome deixam de apresentar níveis elevados deste marcador ${ }^{107}$.

Um aspecto, ainda objeto de debate envolvendo o FNT- $\alpha$ refere-se ao mecanismo pelo qual ocorre aumento deste, em pacientes com IC. Embora inicialmente a idéia prevalente fosse de que o FNT- $\alpha$ poderia apenas ser produzido por células do sistema imune, atualmente vários estudos demonstram que, embora o miócito normal de fato não o produza, quando há falência ventricular FNT- $\alpha$ pode ser sintetizado pelo miocárdio ${ }^{110}$. O gatilho para a produção do FNT- $\alpha$ nesta situação, especula-se, possa ser a própria lesão miocárdica induzida pelo excesso de catecolaminas circulantes ${ }^{111}$. Além disso, ambos receptores para o FNT- $\alpha$ foram identificados na superfície de miócitos cardíacos ${ }^{108}$. Caracteristicamente, uma vez exercido o efeito do FNT- $\alpha$ sobre seus receptores celulares, ocorre uma clivagem destes da superfície celular, sendo liberados na circulação. De fato, níveis elevados dos receptores solúveis do FNT- $\alpha$ foram documentados em pacientes com IC grave, e também parecem se correlacionar com mau prognóstico ${ }^{107}$. No entanto, o papel exato destes receptores nos efeitos biológicos do FNT- $\alpha$ ainda são controversos. Uma hipótese é de que estes possam servir como tampão, impedindo maior ação deletéria do FNT- $\alpha$. In vitro, foi demonstrado que os receptores solúveis podem bloquear e até mesmo reverter os efeitos inotrópico-negativos do FNT- $\alpha$. Por outro lado, especula-se que os receptores possam estabilizar o FNT- $\alpha$, como homodímero, aumentando sua bioatividade comparativa- 
mente à forma inativa dos monômeros ${ }^{47}$. Portanto, os efeitos dos receptores podem ser vistos como dicotômicos, com efeito benéfico a curto prazo, bloqueando os efeitos do FNT- $\alpha$, mas a longo prazo estabilizando-o, aumentando seu efeito biológico e caracterizando uma situação mal-adaptativa. Os efeitos celulares e moleculares decorrentes da atuação do FNT- $\alpha$ sobre seus receptores no miocárdio são vários e incluem indução de apoptose, indução da síntese da enzima óxido nítrico sintetase, depressão da função contrátil, maior aderência dos miócitos à matriz extracelular, este último talvez envolvido na mudança de forma das células, à medida que ocorre dilatação ventricular ${ }^{112,113}$. A indução a uma maior produção de óxido nítrico sintetase leva a um aumento do óxido nítrico, que pode exercer dois tipos de efeitos: um inotrópico negativo, portanto deletério, e outro, promovendo vasodilatação, contrabalançando a vasoconstrição secundária ao aumento do tônus simpático ${ }^{47}$.

Como a dosagem sérica do FNT- $\alpha$ pode ser utilizada clinicamente e se relaciona com a gravidade e o prognóstico da IC, a consolidação do paradigma depende da demonstração de que intervenções terapêuticas sobre esta citocina sejam eficazes. Recentemente, Sliwa e col ${ }^{114}$ publicaram um ensaio clínico randomizado sobre o efeito da pentoxifilina, que suprime a produção de FNT- $\alpha$, em pacientes com IC por miocardiopatia dilatada. Após 6 meses de acompanhamento, pacientes que receberam pentoxifilina apresentaram concentrações séricas mais baixas de FNT- $\alpha$, melhor capacidade funcional e FEVE mais elevada. Portanto, estes achados preliminares sugerem que, no futuro próximo, o paradigma imunoinflamatório possa se consolidar.

\section{Raciocínio clínico versus farmacologia clínica}

A aplicação dos paradigmas que orientam o manejo atual da IC permite discutir a prática médica moderna baseada em evidência. Os médicos têm sido tradicionalmente treinados com base no conceito de que a "clínica é soberana". Por traz deste ensinamento clássico encontram-se dois conceitos: 1) os sintomas e os sinais apresentados pelos pacientes devem trazer as informações fundamentais para o tratamento; 2) o raciocínio lógico, baseado em conceitos fisiopatológicos e farmacológicos, é suficiente para estabelecer as bases "racionais" de manejo. Nos próximos parágrafos apresentaremos argumentos sugerindo que estes conceitos devem ser repensados.

Sinais e sintomas-Os cursos de semiologia ensinam que, em pacientes com IC grave por disfunção sistólica, estertores pulmonares, turgência jugular e edema periférico são indicadores de elevadas pressões de enchimento ventricular. Entretanto, quando Stevenson e Perloff ${ }^{83}$ realizaram medidas hemodinâmicas em 50 pacientes com IC crônica encaminhados para transplante cardíaco, a presença de estertores pulmonares, edema periférico e turgência jugular apresentou uma sensibilidade de apenas 58\%, com especificidade de $100 \%$, para a estimativa de uma pressão capilar pulmonar $>22 \mathrm{mmHg}$. Da mesma forma, pacientes com disfunção sistólica assintomática do VE geralmente não podem ser identificados pela anamnese ou pelo exame físico, necessitando de métodos auxiliares de avaliação da função ventricular, como a ecocardiografia ou a ventriculografia radioisotópica. Como discutido nos paradigmas neuro-humoral e de remodelamento, esses pacientes podem ser grandemente beneficiados pelo tratamento precoce com inibidores da convertase, como demonstrado por diversos ensaios clínicos ${ }^{33,38-44}$. Ao contrário dos ensinamentos clássicos, para esses pacientes, a medicina baseada em evidência recomenda "tratar o exame" e não os sintomas dos pacientes. Desta forma, tanto nas fases iniciais da disfunção ventricular esquerda como nas fases avançadas da IC crônica, as informações da anamnese e do exame físico não são suficientes para um manejo adequado.

Manejo racional da insuficiência cardíaca-Os conceitos sobre tratamento da IC evoluíram muito nas últimas décadas. Como freqüentemente acontece, hipóteses foram inicialmente testadas em modelos animais para, em seguida, serem aplicadas em ensaios clínicos. Porém, o inverso também pode acontecer, quando, a partir de resultados inesperados de ensaios clínicos, novos conceitos passam a ser testados em modelos animais. Apontaremos algumas situações onde o manejo "racional" não foi confirmado por ensaios clínicos.

Até o início dos anos 80, esperava-se que drogas eficazes em seus efeitos hemodinâmicos e na capacidade funcional, também, tivessem benefício na sobrevida. Entretanto, quando agentes inodilatadores, que aumentam a contratilidade, têm efeito vasodilatadores e aumentam a capacidade funcional, foram testados por ensaios clínicos, observou-se que eles aumentavam a mortalidade. O ensaio da vesraninona ${ }^{17}$, um inibidor da fosfodiesterase, demonstrou que doses baixas do medicamento tinham um efeito de melhora da sobrevida, enquanto a dose com efeito inotrópicopositivo mais potente aumentava a mortalidade. Além disso, suspeita-se que parte dos efeitos favoráveis da digoxina nesses pacientes não era relacionada a sua ação inotrópicopositiva, mas ao seu efeito modulador no sistema nervoso autônomo ${ }^{115,116}$. Portanto, a partir destes achados, passouse a compreender que os efeitos das drogas sobre fração de ejeção, vasodilatação, capacidade funcional e sobrevida são independentes.

A administração de bloqueadores de cálcio di-hidropiridínico a pacientes com IC resulta em vasodilatação arteriolar e pequeno efeito inotrópico negativo. Como estes agentes têm efeito favorável na distribuição do fluxo coronário, parecia "racional" administrá-los a pacientes com IC por miocardiopatia isquêmica. Entretanto, o ensaio clínico PRAISE ${ }^{26}$ mostrou que amlodipina diminuiu a mortalidade em pacientes com miocardiopatia dilatada e não naqueles com miocardiopatia isquêmica. Da mesma forma, esperar-se-ia que a amiodarona, por seu potente efeito antiarrítmico, tivesse efeito favorável em pacientes com ICe alta densidade de arritmia ventricular. Entretanto, o ensaio GESICA $^{60}$, que demonstrou efeito favorável da amiodarona na sobrevida, avaliou justamente pacientes sem grande 
densidade de arritmia ventricular. Portanto, ao contrário do raciocínio lógico, baseado no paradigma da arritmia, acredita-se hoje que os efeitos favoráveis da amiodarona estejam relacionados à sua ação betabloqueadora ${ }^{117}$.

O paradigma do remodelamento ventricular foi inicialmente concebido tendo como base o conceito de que a diminuição da pré- e pós-carga do VE poderia diminuir o estresse parietal e, com isso, modular o processo dilatação progressiva pós-infarto. Com a demonstração da eficácia dos inibidores da convertase e ineficácia dos nitratos, a importância dos efeitos tissulares da angiotensina passou a ser mais valorizada. Já que o bloqueio do sistema reninaangiotensina-aldosterona pode trazer efeitos tanto hemodinâmicos como neuro-humorais, é importante mencionar o ensaio clínico V-HeFT II ${ }^{27}$, que comparou o uso de enalapril com a associação de hidralazina e nitrato - drogas essencialmente vasodilatadoras sem efeitos neurohumorais - em pacientes com IC. Embora a associação hidralazina-nitrato tenha produzido os maiores aumentos de FEVE, foi o uso de enalapril que reduziu significativamente a mortalidade e isto se associou com maior redução dos níveis circulantes de noradrenalina. Portanto, aumento da FEVE e maior vasodilatação não são suficientes para impedir a progressão da doença. Isto aparentemente só é observado quando os sistemas anormalmente ativados são bloqueados.

Mesmo quando o pensamento inovador sugere estratégias que contrariam o pensamento vigente, a "nova lógica" gerada por estas idéias merece avaliação objetiva. Como grande parte de outros procedimentos cirúrgicos inovadores, a técnica de Batista de remodelamento cirúrgico do VE foi levada rapidamente de sua concepção para a aplicação em seres humanos, mesmo com pouca ou nenhuma base experimental. Em contraste com o desenvolvimento de novas drogas, que passa por várias etapas de experimentação animal e ensaios clínicos supervisionados por agências regulamentadoras, novas técnicas cirúrgicas são largamente utilizadas sem controle, muito antes de serem avaliadas criteriosamente. Assim como aconteceu com os inibidores da fosfodiesterase de administração oral, a melhora da função ventricular com a cirurgia de Batista pode também ser acompanhada de aumento da mortalidade. Porém, os inibidores da fosfodiesterase de uso oral nunca foram lançados no mercado, exatamente porque antes foram avaliados por ensaios clínicos, enquanto o procedimento cirúrgico está sendo realizado sem maior controle. Estes fatos sugerem que, a exemplo do que acontece para intervenções farmacológicas, normas mais rígidas devam ser instituídas também para a aprovação de procedimentos cirúrgicos. Se de um lado isto poderá limitar o rápido desenvolvimento de técnicas inovadoras eficazes, por outro poderá proteger pacientes mal informados do uso não controlado de técnicas ineficazes. É ainda interessante contrastar a velocidade da incorporação da ventriculectomia parcial com a incorporação do uso de betabloqueadores no manejo de pacientes com IC. Da mesma forma que a ventriculectomia, o conceito de blo- quear o sistema beta-adrenérgico contrariou o pensamento vigente. Entretanto, foram necessários mais de 20 anos e inúmeros ensaios clínicos antes destas drogas serem incorporadas à prática clínica.

A demonstração da eficácia de intervenções terapêuticas é apenas a primeira etapa no processo que leva à aplicação desta intervenção. Mesmo intervenções terapêuticas com eficácia documentada por ensaios clínicos freqüentemente não são aplicadas em um segmento da população, ou são aplicadas de maneira inadequada. Em 1993, quando já estavam disponíveis os resultados dos ensaios clínicos demonstrando efeito protetor de vasodilatadores na insuficiência, um percentual apreciável de pacientes não recebia estes medicamentos em um hospital universitário de nosso meio ${ }^{118}$. Da mesma forma, embora todas as diretrizes formais recomendem doses de inibidores da convertase semelhantes às utilizadas nos ensaios clínicos ${ }^{1,2,34}$, o fato da proteção quanto à mortalidade não poder ser avaliada no manejo individualizado do paciente fez com que a maioria dos médicos prescrevesse doses mais baixas destes agentes. Neste sentido, os resultados preliminares do estudo ATLAS (Packer. Annual Meeting of the American College of Cardiology, Atlanta, EUA, 1998), que comparou doses diferentes de lisinopril em pacientes com IC, indicam que as doses mais elevadas são realmente necessárias para diminuir o número de internações hospitalares. Portanto, este ensaio clínico reforça o conceito de que, para atingir os resultados não quantificáveis na prática clínica individualizada, a prática médica deve tentar reproduzir as intervenções realizadas nos ensaios clínicos.

A indicação de repouso para pacientes com IC até os anos 80 era baseada no raciocínio lógico: como o exercício físico é um indutor do mais importante sintoma da IC - a dispnéia, consequentemente, a atividade física, que induz este sintoma, deveria ser contraindicada. Entretanto, estudos de fisiopatologia mudaram o referencial teórico e ensaios clínicos randomizados demonstraram que a atividade física regular é uma intervenção terapêutica potente quando o objetivo é aumento da capacidade funcional ${ }^{79}$.

\section{Conclusão}

Nos últimos anos, a evolução dos conhecimentos da etiopatogenia e fisiopatologia da IC tem sido rápida. Além disso, a quantificação objetiva da função ventricular tornou-se acessível para a grande maioria dos cardiologistas e foram adequadamente testadas novas formas terapêuticas, facilitando a aplicação mais precisa dos paradigmas estabelecidos. Embora tenha havido uma sensível melhora nas últimas décadas, a mortalidade por IC continua elevada e o custo com internações hospitalares revela que muito precisa ser feito ainda. O desenvolvimento de novos paradigmas e a implementação efetiva dos atuais para toda a população deverá marcar a próxima década de avanços da cardiologia. A análise do desenvolvimento dos paradigmas nos últimos anos também sugere que a clínica deixou de ser soberana. Nos dias de hoje, a farmacologia clínica é soberana. 


\section{Referências}

1. Remme WJ, Cleland JGF, Dargie $\mathrm{H}$ et al - Guidelines for the treatment of heart failure. Eur Heart J 1997; 18: 736-53.

2. Williams J, Bristow MR, Fowler MB et al - Guidelines for the evaluation and management of heart failure. Report of the American College of Cardiology/ American Heart Association Task Force on Practice Guidelines (Committee on Evaluation and Management of Heart Failure). J Am Coll Cardiol 1995; 26 : 1376-98.

3. Ribeiro JP, Clausell N - Em busca de novos paradigmas para o manejo da cardiopatia isquêmica. Arq Bras Cardiol 1997; 69: 1-12.

4. Kass DA, Maugham WL - From E to pressure-volume relations: a broader view. Circulation 1988; 77: 1203-12.

5. Parameshwar J, Keegan J, Sparrow J et al - Predictors of prognosis in severe heart failure. Am Heart J 1992; 123: 421-6.

6. Captopril-Digoxin Multicenter Research Group - Comparative effects of therapy with captopril and digoxin in patiets with mild to moderate heart failure. JAMA 1988; 259: 539-44.

7. DiBianco R, Shabetai R, Kostuk W, Moran J, Schlant RC, Wright R - A comparison of oral milrinone, digoxin, and their combination in the treatment of patients with chronic heart failure. N Engl J Med 1989; 320: 677-83.

8. The Digitalis Investigation Group - The effect of digoxin on mortality and morbidity in patients with heart failure. N Engl J Med 1997; 336: 525-33.

9. White HD, Ribeiro JP, Hartley LH, Colucci WS - Immediate effects of milrinone on metabolic and sympathetic responses to exercise in severe congestive heart failure. Am J Cardiol 1985; 56: 93-8.

10. Ribeiro JP, White HD, Arnold JMO, Hartley LH, Colucci WS - Exercise responses before and after long-term treatment with oral milrinone in patients with severe heart failure. Am J Med 1986; 81: 759-64.

11. Ribeiro JP, White HD, Hartley LH, Colucci WS - Acute increase in exercise capacity with milrinone: lack of correlation with resting hemodynamic responses. Braz J Med Biol Res 1990; 23: 1069-78.

12. Ribeiro JP, Hartley LH, Colucci WS - Effects of acute and chronic pharmacologic interventions on exercise performance in patients with congestive heart failure Heart Failure 1985; 1: 102-11

13. Rohde LE, Ribeiro JP - Agentes inotrópico positivos no manejo da insuficiência cardíaca: bases farmacológico-clínicas. Arq Bras Cardiol 1994; 63: 537-42.

14. Hampton JR, van Veldhulsen DJ, Kleber FX et al - Randomised study of effect of ibopamine on survival in patients with advanced heart failure. Lancet 1997; 349: 971-7.

15. Packer M, Carver JR, Rodeheffer RJ et al - Effect of oral milrinone on mortality in severe chronic heart failure: the PROMISE Study Research Group. N Engl J Med 1991; 35: 1468-75

16. The Xamoterol in Severe Heart Failure Study Group - Xamoterol in severe heart failure. Lancet 1990; 336: 1-6.

17. Feldman AM, Bristow MR, Parmley WW et al - Effects of vesnarinone on morbidity and mortality in patients with heart failure. N Engl J Med 1993; 35: 1468-75.

18. Lubsen J, Just $\mathrm{H}$, Hjalmarsson AC et al - Effect of pimobendan on exercise capacity in patients with heart failure: main results from the Pimobendan in Congestive Heart Failure (PICO) trial. Heart 1996; 76: 223-31.

19. Dies F, Knell MJ, Whitlow $P$ et al - Intermitent dobutamine in ambulatory outpatients with chronic cardiac failure. Circulation 1986; 74(suppl II): II: 38.

20. StevensonLW, Tillisch JH,Hamilton Metal-Importance of hemodynamic response to therapy in predicting survival with ejction fraction $<20 \%$ secondary to ischemic or non-ischemic dilated cardiomyopathy. Am J Cardiol 1990; 66: 1348-54.

21. McAlister FA, Teo KK - The management of congestive heart failure. Postgrad Med J 1997; 73: 194-200.

22. Gradman A, Deedwania P, Cody R et al - Predictors of total mortality and sudden death in mild to moderate heart failure. J Am Coll Cardiol 1989; 14: 564-70

23. Leier CV, Huss P, Magorien, Unverferth DV et al - Improved exercise capacity and differing arterial and venous tolerance during chronic isosorbide dinitrate therapy for congestive heart failure. Circulation 1983; 67: 817-22.

24. Franciosa JA, Goldsmith SR, Cohn JN - Contrasting immediate and long-term effects of isosorbide dinitrate on exercise capacity in congestive heart failure. Am J Med 1980; 69: 559-66.

25. Cohn JN, Archibald DG, Ziesche S et al - Effect of vasodilatory therapy on mortality in chronic congestive heart failure: results of a Veterans Administration Cooperative Study. N Engl J Med 1986; 314: 1547-52.

26. Packer M, O Connor CM, Ghali JK et al - Effect of amlodipine on morbidity and mortality in severe chronic heart failure. N Engl J Med 1996; 335: 1107-14.

27. Cohn JN, Johnson G, Ziesche S et al - A comparison of enalapril with hydralazineisosorbide dinitrate in the treatment of chronic congestive heart failure. $\mathrm{N} \mathrm{Engl} \mathrm{J}$ Med 1991; 325: 303-10.
28. Packer M - The neurohumoral hypothesis: a theory to explain the mechanism of disease progression in heart failure. J Am Coll Cardiol 1992; 20: 248-54.

29. Johnston CI - Tissue angiotensin converting enzyme in cardiac and vascular hypertrophy, repair, and remodeling. Hypertension 1994; 23: 258-68.

30. Hirsch AT, Talsness CE, Schunkert, Paul M, Dzau VJ - Tissue-specific activation of cardiac angiotensin converting enzyme in experimental heart failure. Circ Res 1991; 69: 475-82

31. Francis GS, Benedict C, Johnstone DE et al - Comparison of neuroendocrine activation in patients with left ventricular dysfunction with or without congestive heart failure. A substudy of the Studies of Left Ventricular Dysfunction (SOLVD). Circulation 1990; 82: 1724-9.

32. Ferreira AS - Bradykinin-potentiating factor (BPF) present in the venom of Bothrops jararaca. Brit J Pahrmacol 1965; 24: 163-9.

33. The SOLVD Investigators - Effect of enalapril on mortality and the development of heart failure in asymptomatic patients with reduced left ventricular ejection fraction. N Engl J Med 1992; 327: 685-91.

34. The SOLVD Investigators - Effect of enalapril on survival in patients with reduced left ventricular ejection fractions and congestive heart failure. $\mathrm{N}$ Engl J Med 1991; 325: 293-302.

35. The CONSENSUS Trial Study Group - Effects of enalapril on mortality in severe heart failure. N Engl J Med 1987; 316: 429-35.

36. Pitt B, Segal R, Martinez FA, Meurers G, Cowley A, Thomas I et al - Randomised trial of losartan versus captopril in patients over 65 with heart failure (Evaluation of Losartan in the Elderly Study, ELITE). Lancet 1997; 349: 747-52.

37. White HD, Norris RM, Brown MA, Brandt PWT, Whitelock RML, Wild CJ - Left ventricular end-systolic volume as the major determinant of survival after recovery from myocardial infarction. Circulation 1987; 76: 44-51.

38. Pfeffer MA, Braunwald E, Moyé LA et al - Effect of captopril on mortality and morbidity in patients with left ventricular dysfunction after myocardial infarction. Results of the Survival and Ventricular Enlargement Trial. N Engl J Med 1992; 327: 669-77.

39. The Acute Infarction Ramipril Efficacy (AIRE) Study Investigators - Effect of ramipril on mortality and morbidity of survivors of acute myocardial infarction with clinical evidence of heart failure. Lancet 1993; 342: 821-8.

40. Gruppo Italiano per lo Studio della Sopravivenza nell' infarto miocardico.GISSI3 - Effects of lisinopril and transdermal glyceril trinitrate singly or together on 6 week mortality and ventricular function after myocardial infarction. Lancet 1994; 343: 1115-22

41. Chinese Cardiac Study Collaborative Group - Oral captopril versus placebo among 13634 patients with suspected acute myocardial infarction: interim report from the Chinese Cardiac Study (CCS-1). Lancet 1995; 345: 686-7.

42. ISIS-4 Collaborative Group - ISIS-4: a randomized factorial trial assessing early oral captopril, oral mononitrate, and intravenous magnesium sulphate in 58050 patients with suspected myocardial infarction. Lancet 1995; 345: 669-85.

43. Ambrosioni E, Borghi C, Magnani B, for the Survival of Myocardial Infarction Long-term Evaluation (SMILE) Study Investigators - The effect of angiotensinconverting-enzyme inhibitor zofenopril on mortality and morbidity after anterior myocardial infarction. N Engl J Med 1995; 332: 80-5.

44. Hall AS, Murray GD, Ball SG, on behalf of the AIREX Study Investigators Follow-up study of patients randomly allocated ramipril of placebo for heart failure after acute myocardial infarction: AIRE Extension (AIREX) Stduy. Lancet 1997; 349: 1493-7.

45. Lucchese FA, Frota Filho JD, Blacher C, Pereira W, Roso JA, Leaes P - Partial left ventriculectomy: a casuistry of 38 cases. J Am Coll Cardiol 1998; 31(suppl A): $376 \mathrm{~A}$

46. Starling RC, Young JB, Buda T, Smedira N, Goormastic M, McCarthy PM Intermediate results of partial ventriculectomy for dilated cardiomyopathy. J Am Coll Cardiol 1998; 31(suppl A): 376A

47. Shan K, Kurrelmeyer K, Seta Y et al - The role of cytokines in disease progression in heart failure. Curr Opin Cardiol 1997; 12: 218-23.

48. Singh N, Dhalla A, Seneviratne C, Singal P - Oxidative stress and heart failure Moll Cell Biochem 1995; 147: 77-81

49. Colucci WS, Ribeiro JP, Rocco MB et al - Impaired chronotropic response to exercise in patients with congestive heart failure. Role of postsynaptic betaadrenergic desensitization. Circulation 1989; 80: 314-23.

50. Cohn JN, Levine TB, Olivari MT et al - Plasma norepinephrine as a guide to prognosis in patients with chronic congestive heart failure. N Engl J Med 1984; 311: 819-23.

51. Waagstein F, Hjalmarson A, Varnauskas E, Wallentin I - Effect of chronic betaadrenergic receptor blockade in congestive cardiomyopathy. Br Heart J 1975; 37: $1022-36$

52. Heidenreich P, Lee T, Massie B - Effect of beta-blockade on mortality in patients with heart failure: a meta-analysis of randomized clinical trials. J Am Coll Cardiol 1997; 30: 27-34 
53. Waagstein F, Bristow MR, Swedberg K et al - Beneficial effects of metoprolol in idiopathic dilated cardiomyopathy. Lancet 1993; 342: 1743-50.

54. CIBIS Investigators and Committees - A randomized trial of beta-blockade in heart failure: the Cardiac Insufficiency Bisoprolol Study (CIBIS). Circulation 1994; 90: 1765-73.

55. Packer M, Bristow MR, Cohn JN et al - The effect of carvedilol on morbidity and mortality in patients with chronic heart failure. N Engl J Med 1996; 334: 1349-55.

56. Schwartz SM - Cell death and the caspase cascade. Circulation 1998; 97: 227-9.

57. The Cardiac Arrhythmia Supression Trial (CAST) Investigators - CAST mortality and morbidity. Treatment versus placebo. N Engl J Med 1991; 324: 781-8.

58. The Cardiac Arrhythmia Supression Trial II Investigators - Effect of the antiarrhythmic agent moricizine on survival after myocardial infarction. N Engl J Med 1992; 327: 227-33.

59. Mitchel LB, Duff HJ, Manyari DE, Wyse DG - A randomized clinical trial of the noninvasive and invasive approaches to drug therapy of ventricular tachycardia. N Engl J Med 1987; 317: 1681-7.

60. Doval HC, Nul DR, Grancelli HO, Perrone SV, Bortman GR, Curiel R Randomised trial of low-dose amiodarone in severe congestive heart failure. Grupo de Estudio de la Sobrevida en la Insuficiencia Cardiaca en Argentina Lancet 1994; 344: 493-10.

61. Singh SN, Fletcher RD, Fisher SG et al - Amiodarone in patients with congestive heart failure and asymptomatic ventricular arrhythmia. Survival Trial of Antiarrhythmic Therapy in Congestive Heart Failure. N Engl J Med 1995; 333: 77-82.

62. Julian DG, Camm AJ, Frangin G et al - Randomised trial of effect of amiodarone on mortality in patients with left ventricular dysfunction after recent myocardial infarction: EMIAT. Lancet 1997; 349: 667-74.

63. Cairns JA, Connolly SJ, Roberts R, Gent M, for the Canadian Amiodarone Myocardial Infarction Arrhythmia Trial Investigators - Randomised trial of outcome after myocardial infarction in patients with frequent or repetitive ventricular premature depolarisations: CAMIAT. Lancet 1997; 349: 675-82.

64. Moss AJ, Hall WJ, Cannom DS et al - Improved survival with an implanted defibrillator in patients with coronary artery disease at high risk for ventricular arrhythmia. N Engl J Med 1996; 335: 1933-40.

65. The Antiarrhythmics Versus Implantable Defibrillatos (AVID) Investigators - A comparison of antiarrhythmic-drug therapy with implantable defibrillators in patients ressucitated from near-fatal ventricular arrhythmias. N Engl J Med 1997; 337: 1576-83.

66. Bigger JT, for the Coronary Artery Bypass Graft (CABG) Patch Trial Investigators - Prophylatic use of implanted cardiac defibrillators in patients at high risk for ventricular arrhythmias after coronary-artery bypass graft surgery. N Engl J Med 1997; 337: 1569-75.

67. Vasan RS, Benjamin EJ, Levy D - Prevalence, clinical features and prognosis of diastolic heart failure: an epidemiologic perspective. J Am Coll Cardiol 1995; 26: $1565-74$

68. Goldsmith SR, Dick C - Differentiating systolic from diastolic heart failure: pathophysiologic and therapeutic considerations. Am J Med 1993; 95: 645-55.

69. Boluyt MO, O Neill L, Meredith AL et al - Alterations in cardiac gene expression during the transition from stable hypertrophy to heart failure: marked upregulation of genes encoding extracellular matrix components. Cir Res 1994; 75: 23-32.

70. Doering CW, Jalil JE, Janicki JS et al - Collagen network remodeling and diastolic stiffnes of the rat ventricle with pressure overload hypertrophy. Cardiovasc Res 1988; 22: 686-95.

71. Hess OM, Ritter M, Schneider J, Grimm J, Turina M, Krayenbuehl HP - Diastolic stiffness and myocardial structure in aortic valve disease before and after valve replacement. Circulation 1984; 69: 855-65.

72. Friedrich SP, Lorell BH, Rousseau MF et al - Intracardiac angiotensinconverting enzyme inhibition improves diastolic function in patients with left ventricular hypertrophy due to aortic stenosis. Circulation 1994; 90: 2761-71.

73. Gottlieb SS, Dickstein K, Fleck E et al-Hemodynamic and neurohormonal effects of angiotensin II antagonist losartan in patients with congestive heart failure. Circulation 1993; 88: 1602-09.

74. Weber KT - Extracellular matrix remodeling in heart failure - A role for de novo angiotensin II generation. Circulation 1997; 96: 4065-82.

75. Arnold JMO, Ribeiro JP, Colucci WS - Muscle blood flow during forearm exercise in patients with severe heart failure. Circulation 1990; 82: 465-72.

76. Drexler H, Riede U, Münzel T, König H, Funke E, Just H - Alterations of skeletal muscle in chronic heart failure. Circulation 1992; 85: 1751-9.

77. Lee TH, Shammash JB, Ribeiro JP, Hartley LH, Sherwood J, Goldman L Prediction of maximum oxygen uptake from clinical data: performance of the specific activity scale. Am Heart J 1988; 115: 203-4.

78. Szlachcic J, Massie BM, Kramer BL, Topic N, Tubau J - Correlates and prognostic implication of exercise capacity in chronic heart failure. Am J Cardiol 1985; 55: $1037-42$.

79. Coats AJS, Adamopoulos S, Meyer TE, Conway J, Sleight P - Effects of physical training in chronic heart failure. Lancet 1990; 335: 63-6.
80. Hornig B, Maier V, Drexler H - Physical training improves endothelial function in patients with chronic heart failure. Circulation 1996; 93: 210-4.

81. Hambrecht R, Niebauer J, Fiehn E et al - Physical training in patients with stable chronic heart failure: effects on cardiorespiratory fitness and ultrastructural abnormalities of leg muscles. J Am Coll Cardiol 1995; 25: 1239-49.

82. Stevenson LW, Brunken RC, Belil D et al - Afterload reduction with vasodilators and diuretics decreases mitral valve regurgitation during upright exercise in advanced heart failure. J Am Coll Cardiol 1990; 15: 174-80.

83. Stevenson LW, Perloff JK - The limited reliability of physical signs for the estimation of hemodynamics in chronic heart failure. JAMA 1989; 261: 884-8.

84. Stevenson LW, Tillisch JH - Maintenance of cardiac output with normal filling pressures in dilated heart failure. Circulation 1986; 74: 1303-8.

85. Rohde LE, Polanczyk CA, Ribeiro JP, Clausell N - Otimização das indicações e do manejo terapêutico de pacientes referidos para transplante cardíaco. Arq Bras Cardiol 1996; 67: 118-24.

86. Steimle AE, Stevenson LW, Chelimsky-Fallick C et al - Sustained hemodynamic efficacy of therapy tailored to reduce filling pressures in survivors with advanced heart failure. Circulation 1997; 96: 1165-72.

87. Belch J, Bridges A, Scott N, Chopra M - Oxygen free radicals and congestive heart failure. Br Heart J 1991; 65: 245-8.

88. Kiowski W, Sutsch G, Hunziker P et al - Evidence for endothelin-1 mediated vasoconstriction in severe chronic heart failure. Lancet 1995; 36: 732-6.

89. Sakai S, Miyauchi T, Sakurai T et al - Endogenous endothelin-1 participates in the maintenance of cardiac function in rats with congestive heart failure: marked increase in endothelin-1 production in the failing heart. Circulation 1996; 93 : 1214-22.

90. Pacher R, Stanek B, Hulsmann M et al - Prognostic impact of big endothelin-1 plasma concentrations compared with invasive hemodynamic evaluation in severe heart failure. J Am Coll Cardiol 1996; 27: 633-41.

91. Weber KT, Sun Y, Guarda E - Structural remodeling in hypertensive heart disease and the role of hormones. Hypertension 1994; 23: 869-77.

92. Sakai S, Miyauchi T, Yamaguchi I, Goto K, Sugishita Y - Inihibition of myocardial endothelin pathway improves long-term survival in heart failure. Letters to Nature 1996; 384: 353-5.

93. Katz SD, Krum H, Khan T, Knecht M - Exercise-induced vasodilation in forearm circulation of normal subjects and patients with congestive heart failure: role of endothelium-derived nitric oxide. J Am Coll Cardiol 1996; 28: 585-90.

94. Lindsay DC, Anand IS, Bennett JG et al - Ultrastructural analysis of of skeletal muscle: microvascular dimensions and basement membrane thickness in chronic heart failure. Eur Heart J 1994; 15: 1470-6.

95. Katz S - Mechanisms and implications of endothelial dysfunction in congestive heart failure. Curr Opin Cardiol 1997; 12: 259-64.

96. Drexler H, Kurz S, Jeserich M, Munzel T, Hornig B - Effect of chronic angiotensinconverting enzyme inhibition on endothelial function in patients with chronic heart failure. Am J Cardiol 1995; 76: 13E-18E.

97. Schwarz M, Katz SD, Demopoulos L, Hirsch H, Yuen JL, Jondeau G et al Enhancement of endothelium-dependent vasodilation by low-dose nitroglycerin in patients with congestive heart failure. Circulation 1994; 89: 1609-14.

98. Colucci WS - Molecular and cellular mechanisms of myocardial failure. Am J Cardiol 1997; 80: 15L-25L.

99. Narula J, Haider N, Virmani R et al - Programmed myocyte death in end-stage heart failure. N Engl J Med 1996; 335: 1182-9.

100. Olivetti G, Abbi R, Quaini F et al - Apoptosis in the failing human heart. N Engl J Med 1996; 336: 1131-41

101. Feuerstein GZ, Yue TL - Apoptosis and the heart. Basic and applied myology 1996; 6: 221-5.

102. Richardson D, McKenna W, Bristow M et al - WHO/ISFC Taskc Force definition and classification of cardiomyopathies. Circulation 1996; 93: 23-4.

103. Dec GW, Fuster V - Idiopathic dilated cardiomyopathy. N Engl J Med 1994; 331 : 1564-75.

104. Limas CJ, Goldenberg IF, Limas C - Soluble interkeukin-2 receptor levels in patients with dilated cardiomyopathy. Circulation 1995; 91: 631-4.

105. Mason JW, O'Connel JB, Herskowitz A et al - A clinical trial of immunosupressive therapy for myocarditis. N Engl J Med 1995; 333: 269-75.

106. Maisch B, Hufnagel G, Schönian U, Hengstenberg C, for the ESETCID Investigators - The European Study for Epidemiology and Treatment of Cardiac Inflammatory Diseases (ESETCID). Eur Heart J 1995; 16(suppl O): 173-5.

107. Ferrari R, Bachetti T, Confortini R et al - Tumor necrosis factor soluble receptors in patients with various degrees of congestive failure. Circulation 1995; 92 : 1479-86.

108. Torre-Amione G, Kapadia S, Lee J et al - Tumor necrosis factor-alpha and tumor necrosis factor receptors in the failing heart. Circulation 1996; 93: 704-11.

109. Torre-Amione G, Kapadia S, Benedict C, Oral H, Young JB, Mann DL Proinflammatory cytokines levels in patients with depressed left ventricular ejection fraction: a report from the studies of left ventricular dysfunction (SOLVD). J Am Coll Cardiol 1996; 27: 1201-6. 
110. Mann DL, Lee-Jackson D, Yokoyama T - Tumor necrosis factor alpha and cardiac remodeling. Heart Failure 1995; 166-76.

111. Mann DL, Young JB - Basic mechanisms in congestive heart failure: recognizing the role of proinflammatory cytokines. Chest 1994; 105: 897-904.

112. Habib FM, Springall DR, Davies GJ, Oakley CM, Yacoub MH, Polak JM - Tumor necrosis factor and inducible nitric oxide synthase in dilated cardiomyopathy. Lancet 1996; 347: 1151-5.

113. Krown KA, Page MT, Nguyen C et al - Tumor necrosis factor alpha-induced apoptosis in cardiac myocytes:involvement of the sphingolipid signaling cascade in cell death. J Clin Invest 1996; 98: 2854-65.

114. Sliwa K, Skudickhy D, Candy G, Wisenbauch T, Sareli P - Randomised investigation of effects of pentoxifylline on left ventricular performance in idiopathic dilatated cardiomyopathy. Lancet 1998; 351: 1091-3.
115. Ferguson DW, Berg WJ, Sanders JS, Roach PJ, Kempf JS, Kienzle MG Sympatho-inhibitory responses to digitalis glycosides in heart failure patients: direct evidence from sympathetic neural recordings. Circulation 1989; 80: 65-77.

116. Covit AB, Shaer GL, Laragh JH, Cody RJ - Suppression of the renin-angiotensin system by intravenous digoxin in chronic congestive heart failure. Am J Med 1983; 75: 445-7.

117. Rohde LE, Polanczyk CA, Moraes RS, Ferlin EL, Ribeiro JP - Effect of partial arrhythmia supression of amiodarone on heart rate variability of patients with congestive heart failure. Am Heart J 1998; 136: 31-6.

118. Grossman G, Mussnich H, Wainstein M, Polanczyk C, Ribeiro JP - Padrão de utilização clínica dos digitálicos: necessidade de reavaliação. Arq Bras Cardiol 1992; 59; 195-201. 